\title{
Adolescent smokers seen in general practice: health, lifestyle, physical measurements, and response to antismoking advice
}

\author{
Joy Townsend, Helen Wilkes, Andrew Haines, Martin Jarvis
}

\section{Abstract}

Objective-To compare physical, lifestyle, and health characteristics of adolescent smokers and non-smokers and their initial response to antismoking counselling.

Design-Adolescents aged 13, 15, and 17 years were identified from age-sex registers and invited by letter for a general practice health check.

Setting-Three general practices in the MRC general practice research framework.

Main outcome measures-Blood pressure, body mass index, saliva cotinine concentration, peak flow rate, alcohol consumption, exercise, duration of sleep, and stated persistent health problems.

Results $-73 \%$ of the adolescents (491) attended for the health check. A total of $68(14 \%)$ were regular smokers. Those who had never smoked regularly had a significantly lower systolic blood pressure than regular smokers by age 17 (by $6 \mathrm{~mm} \mathrm{Hg;}=0.025$ ) despite a significantly higher body mass index (by $1.5 ; p<0.001)$. Cotinine concentrations increased with smoking exposure, from $0.7 \mathrm{ng} / \mathrm{ml}$ when no family member smoked to $155 \mathrm{ng} / \mathrm{ml}$ in active smokers of six or more cigarettes a week. Significantly more regular smokers than never regular smokers drank $\geqslant 8 \mathrm{~g}$ alcohol a day $\left(\chi^{2}=15.2\right.$ adjusted for age and sex $p<0.001)$; regular smokers exercised less $(1.0 \mathrm{hrs} /$ week in boys and $0.8 \mathrm{hrs} /$ week in girls $v$ $3.4 \mathrm{hrs} /$ week in boys and $2.2 \mathrm{hrs} /$ week in girls; $\mathrm{p}<0.001)$ and slept less $(8.0 \mathrm{hrs} /$ night $v 8.5 \mathrm{hrs} /$ night at age $17 ; p<0.005)$. Persistent health problems, mostly asthma or allergic symptoms, were reported by $25 \%(17 / 68)$ of the smokers and $16 \%(60 / 381)$ of the non-smokers. Of the smokers given counselling, $60 \%$ (26/43) made an agreement with the practice doctor or nurse to give up smoking.

Conclusion-General practice is an appropriate setting for adolescents to receive advice on healthy lifestyle, which should not focus solely on smoking.

staff

Helen Wilkes, MSc, scientific staff

University College and Middlesex School of

Medicine, Whittington

Hospital, London N195NF

Andrew Haines, MD, professor of primary health care

ICRF Health Behaviour

Unit, Institute of

Psychiatry, London

SE5 8AF

Martin Jarvis, MPHIL, senior

scientist

Correspondence to:

Ms Townsend.

BMJ 1991;303:947-50 16 year olds were off school for illness during a previous four week period) and weight are other health problems among teenagers. ${ }^{67}$

The main opportunity for health education to children is through school programmes, but the overall effect of education on smoking prevalence so far has been disappointing in the United Kingdom and United States. ${ }^{389}$ Research and policy surveys conclude that there is a need for new methods of intervention, recognising that most teenagers will experiment with cigarette smoking. They recommend that smoking intervention be integrated with advice on a range of health behaviours."

Antismoking intervention in general practice is effective in adults ${ }^{10-12}$ and is one of the most cost effective methods of improving health.$^{13}{ }^{14}$ Despite the importance of adolescence as a transition to adult lifestyle very little has been written about the health of teenagers seen in general practice. This study was therefore undertaken to examine aspects of adolescent lifestyle and the reaction of adolescents to intervention to reduce smoking. We report, firstly, the smoking habits of teenagers in the study and smokers' and nonsmokers' physical measurements; secondly, differences in their lifestyles; thirdly, differences in their health problems; and, finally, smokers' initial response to antismoking advice.

\section{Methods}

Three general practices in the Medical Research Council's general practice research framework (in an inner city area, a country town, and a Welsh valley) invited their patients aged 13, 15, and 17 for an appointment at the practice. The age range was chosen to cover the period of most rapid recruitment to smoking. Very few of the 13 years olds but more of the 15 year olds were expected to be regular smokers, whereas the prevalence of smoking of the 17 year olds was expected to be nearer to adult levels. ${ }^{2}$ To avoid bias towards or against smokers responding, the invitation made no mention of particular concern regarding smoking. Non-attenders were sent second and, where necessary, third appointments. Interviews took place between April and October 1989. Respondents were interviewed by the practice nurse for baseline data concerning their health, exercise, diet, alcohol consumption, their own and their family's smoking habits, sleep, and, for girls, whether taking oral contraception. Height, weight, and systolic and diastolic blood pressure (two readings) were measured and a saliva specimen, which the young person was told would measure exposure to tobacco smoke, taken for cotinine assay.

Two thirds of the adolescents were randomly assigned to see the doctor or practice nurse to discuss problems arising from the baseline interview. Risks of smoking, attitudes to smoking, and ways to refuse a cigarette were discussed, and information on safe drinking, healthy eating, and exercise given both verbally and in a pamphlet to be taken home. The extra risks of smoking and taking the contraceptive pill were discussed. Expired carbon monoxide was measured 
and the implications of the finding explained. For smokers there was discussion of smoking habits, and specific counselling was offered on stopping smoking. Each smoker was given a pamphlet ${ }^{15}$ with general guidance on useful approaches to cessation and a leaflet ${ }^{16}$ with more specific indications according to the main expressed reason for smoking. Non-attenders were sent a questionnaire on their smoking habits.

Statistical analysis was by analysis of variance (parametric and non-parametric), $\chi^{2}$ test, $t$ test, and Fisher's exact test.

\section{Results}

Of the 677 eligible teenagers, 491 (73\%) attended for interview. The response rate varied from $77 \%$ for 13 and 15 year olds to $66 \%$ for 17 year olds. Response rate was the same in boys and girls.

\section{SMOKING PREVALENCE}

A regular smoker was defined, in accordance with the Office of Population Censuses and Surveys convention for children's smoking, as smoking at least one cigarette a week. Overall, $28 \%$ (45) of the 17 year olds, $11 \%$ (19) of the 15 year olds, and 3\% (4) of the 13 year olds were regular smokers (table I). By the age of 17 , $88 \%$ of those currently smoking at all (42/48) smoked at least one cigarette a day. Girls were more likely than boys to smoke, and this was so at each age group. There was no difference in smoking rates by social class; $12 \%$ (21/171) of children from households headed by a nonmanual worker, $13 \%(33 / 251)$ from those headed by a manual worker, and $12 \%(6 / 50)$ from those with a head of household "not in paid employment" smoked regularly.

The questionnaire to non-attenders was returned by $42 \%(78 / 186)$, but movers and wrong addresses were concentrated in the non-attenders so the real response rate is probably higher. The questionnaire showed no differences in smoking rates between attenders and non-attenders.

A clear dose-response relation was apparent between smoking habit and mean cotinine concentration, which increased from $1 \mathrm{ng} / \mathrm{ml}$ in never smokers to $155 \mathrm{ng} / \mathrm{ml}$ in those smoking more than six cigarettes a week (table II). Six of the ex-smokers had cotinine concentrations exceeding $14 \mathrm{ng} / \mathrm{ml}$, a suggested cut off for differentiating smokers and non-smokers ${ }^{2}{ }^{17}$; this implies that the status of ex-smoker was in some cases an intention

TABLE I-Smoking prevalence by age and sex

\begin{tabular}{|c|c|c|c|c|c|c|}
\hline & \multicolumn{3}{|c|}{$\%$ (No) of boys } & \multicolumn{3}{|c|}{$\%$ (No) of girls } \\
\hline & $\begin{array}{c}\text { Age } \\
13 \\
(\mathrm{n}=80)\end{array}$ & $\begin{array}{c}\text { Age } \\
15 \\
(\mathbf{n}=80)\end{array}$ & $\begin{array}{c}\text { Age } \\
17 \\
(\mathbf{n}=72)\end{array}$ & $\begin{array}{c}\text { Age } \\
13 \\
(\mathrm{n}=73)\end{array}$ & $\begin{array}{c}\text { Age } \\
15 \\
(\mathrm{n}=98)\end{array}$ & $\begin{array}{c}\text { Age } \\
17 \\
(\mathrm{n}=88)\end{array}$ \\
\hline Never smoked & $83(66)$ & $64(51)$ & $44(32)$ & $75(55)$ & $65(64)$ & $39(34)$ \\
\hline Tried smoking & $12(10)$ & $20(16)$ & $19(14)$ & $10(7)$ & $14(14)$ & $21(18)$ \\
\hline $\begin{array}{l}\text { Former regular smoker } \\
\text { Smokers: }\end{array}$ & $4(3)$ & $8(6)$ & $8(6)$ & $8(6)$ & $6(6)$ & $9(8)$ \\
\hline$<1$ cigarette/week & & $1(1)$ & $3(2)$ & $3(2)$ & $1(1)$ & $1(1)$ \\
\hline $1-6$ cigarettes/week & $1(1)$ & $1(1)$ & & $1(1)$ & $4(4)$ & $3(3)$ \\
\hline$>6$ cigarettes/week & & $6(5)$ & $25(18)$ & $3(2)$ & $9(9)$ & $27(24)$ \\
\hline
\end{tabular}

TABLE II-Cotinine and carbon monoxide concentrations in adolescents. Values are geometric means

\begin{tabular}{|c|c|c|}
\hline & $\underset{(\mathrm{ng} / \mathrm{ml})}{\text { Cotinine }^{\star}}$ & $\begin{array}{c}\text { Carbon } \\
\text { monoxidef } \\
(\mathrm{ppm})\end{array}$ \\
\hline Never smoked & $1.0(n=269)$ & $1 \cdot 0(n=199)$ \\
\hline Tried smoking & $1.5(n=67)$ & $1 \cdot 1(n=51)$ \\
\hline Ex-smoker & $2 \cdot 6(n=34)$ & $2 \cdot 8(n=23)$ \\
\hline \multicolumn{3}{|l|}{ Smoker: } \\
\hline$<$ l cigarette/week & $5 \cdot 4(n=7)$ & $4 \cdot 8(n=7)$ \\
\hline 1-6 cigarettes/week & $17 \cdot 0(n=9)$ & $4 \cdot 6(n=8)$ \\
\hline$>6$ cigarettes/week & $155 \cdot 2(\mathrm{n}=51)$ & $10 \cdot 3(n=35)$ \\
\hline
\end{tabular}

Measured in a random subsample; $+F=9.5, \mathrm{p}<0.001$.
TABLE III-Mean (SD) systolic blood pressure $(\mathrm{mm} \mathrm{Hg})$ at age 17

\begin{tabular}{lcc}
\hline & $\begin{array}{c}\text { Never regular smoker } \\
(\mathbf{n}=123)\end{array}$ & $\begin{array}{c}\text { Regular smoker } \\
(\mathbf{n}=55)\end{array}$ \\
\hline Boys: & $113 \cdot 2(14 \cdot 9)$ & $106 \cdot 5(15 \cdot 7)$ \\
Girls & $107 \cdot 0(13 \cdot 9)$ & $102 \cdot 0(14 \cdot 7)$ \\
\hline
\end{tabular}

$F=5 \cdot 1, \mathrm{p}=0 \cdot 025$.

TABLE IV-Mean (SD) body mass index of adolescent smokers and non-smokers

\begin{tabular}{lcc}
\hline & Never regular smoker & Regular smoker \\
\hline Boys: & $18 \cdot 9(2 \cdot 5)$ & $19 \cdot 4^{\star}$ \\
13 years & $19 \cdot 8(2 \cdot 5)$ & $23 \cdot 1(3 \cdot 2)$ \\
15 years & $22 \cdot 1(3 \cdot 1)$ & $23 \cdot 5(4 \cdot 2)$ \\
17 years & & \\
Girls: & $20 \cdot 1(3 \cdot 1)$ & $23 \cdot 8(3 \cdot 7)$ \\
13 years & $21 \cdot 8(3 \cdot 3)$ & $21 \cdot 1(3 \cdot 2)$ \\
15 years & $22 \cdot 3(3 \cdot 5)$ & $24 \cdot 0(3 \cdot 6)$ \\
\hline years & & \\
\hline
\end{tabular}

^One subject.

rather than a fact, or of very recent origin. Four never smokers had cotinine concentrations exceeding $14 \mathrm{ng} /$ $\mathrm{ml}$ (the highest was $22 \mathrm{ng} / \mathrm{ml}$ ): three lived with a parent who smoked and may have been registering heavy passive exposure. A similar but less steep dose-response relation was found between smoking habit and mean carbon monoxide concentration. Saliva cotinine assays of those who had never smoked gave a clear response to passive smoking exposure from the family, rising from $0.7 \mathrm{ng} / \mathrm{ml}$ where no family member smoked, $1.4 \mathrm{ng} / \mathrm{ml}$ where father but not mother smoked, $2 \cdot 2 \mathrm{ng} / \mathrm{ml}$ where mother but not father smoked, $2.6 \mathrm{ng} / \mathrm{ml}$ where sibling but not parents smoked, and $4 \cdot 2 \mathrm{ng} / \mathrm{ml}$ where both parents smoked $(F=22 \cdot 8, \mathrm{p}<0 \cdot 001)$. The difference between those exposed to siblings' smoking and those exposed to no family smoking was significant $(p=0.03$, Mann-Whitney test).

PHYSICAL MEASUREMENTS OF SMOKERS AND NON-SMOKERS

Systolic blood pressure increased with age and was higher for boys than for girls. Regular smokers aged 17 had a systolic blood pressure significantly lower than that of those who had never smoked regularly $(F=5 \cdot 1$, $\mathrm{p}=0.025$; table III). Diastolic blood pressure also increased with age and was higher for boys but did not vary by smoking habit.

Mean weight increased with age, boys being on average heavier than girls at age 15 . At 17 , regular smokers were significantly heavier than those who had never smoked regularly $(F=5.9, \mathrm{p}=0.02$ adjusted for sex). Boys aged 17 who smoked regularly were $6 \cdot 2 \mathrm{~kg}$ heavier and girls $4.1 \mathrm{~kg}$ heavier than those who had never smoked regularly. Mean height did not vary with smoking habit. Regular smokers had a significantly higher body mass index than those who had never smoked regularly $(p<0.001$ for boys and girls, Kruskal-Wallis test; table IV).

Thirty per cent (147) of the adolescents thought they were overweight and 14\% (68) underweight. Smokers were particularly likely to think they were overweight (57\% (39) v $24 \%$ (91) of those who had never smoked regularly; $\left.\chi^{2}=26 \cdot 1, \mathrm{df}=1, \mathrm{p}<0 \cdot 05\right)$. Compared with boys, girls considered themselves overweight at a lower body mass index and underweight at a higher body mass index and so had a narrower concept of acceptable weight.

\section{LIFESTYLE}

Alcohol was consumed weekly by $44 \%$ (68) of the 17 year olds, $12 \%$ (20) of the 15 year olds, and $2 \%(3)$ of the 13 year olds. More boys than girls reported weekly drinking: $25 \%(52 / 205)$ compared with $17 \%(40 / 231)$. Consumption of seven or more units of alcohol in the 
previous week (that is, $8 \mathrm{~g}$ alcohol or more a day) was reported by $27 \%(17 / 64)$ regular smokers, $9 \%(24 / 248)$ never regular smokers, and $4 \%(1 / 26)$ ex-smokers aged 15 or $17\left(\chi^{2}=15 \cdot 2\right.$ adjusted for age and sex, $\mathrm{df}=2$, $\mathrm{p}<0.001)$.

Boys exercised for a median of 3.0 hours and girls for 2.0 hours a week. Never regular smokers exercised for 3.4 hours a week (boys) and $2 \cdot 2$ hours (girls) compared with 1.0 hours (boys) and 0.8 hours (girls) who smoked regularly. Difference in exercise by smoking habit was significant $(p<0.001)$ for both boys and girls (KruskalWallis test).

By 17 years regular smokers slept a mean of $8 \cdot 0$ hours a night, which is significantly less than never regular smokers $(8.5$ hours) while ex-smokers slept 8.8 hours $(F=2.5, \mathrm{p}<0.05)$. There was no difference by sex. Thirteen year olds slept on average 9.5 hours per night, 15 year olds $9 \cdot 0$ hours, and 17 year olds $8 \cdot 4$ hours.

\section{HEALTH}

Persistent health problems were reported by $25 \%$ $(17 / 68)$ regular smokers and $16 \%(60 / 381)$ never regular smokers $\left(\chi^{2}=3 \cdot 5, \mathrm{df}=1, \mathrm{p}=0 \cdot 06\right)$. Smokers of all ages and both sexes consistently reported more problems. This was particularly apparent for 17 year old girls.

The most commonly recorded problem was asthma, reported by $12 \%(8 / 68)$ regular smokers and $8 \%$ (32/381) never regular smokers. Of those reporting asthma, 20\% (9/44) were smokers. Health problems were most common $(28 \%, 14 / 50)$ where the head of household was not in paid employment, compared with $16 \%(14 / 251)$ where he or she was a manual worker and $12 \%(21 / 171)$ where a non-manual worker $\left(\chi^{2}\right.$ for trend $=6 \cdot 1, p=0 \cdot 01)$. The prevalence of health problems by social class was independent of smoking habit.

Four per cent of 15 year old girls (4/98) and $26 \%$ of 17 year old girls $(23 / 88)$ were taking oral contraceptives. Girls who were ex-smokers were most likely to be taking the pill $(63 \%(5 / 8)$ compared with $23 \%(18 / 80)$ at age $\left.17, \chi^{2}=5.9, p<0.02\right)$. Of the 17 year old girls, $8 \%$ (7/88) were current smokers taking the pill.

There was no significant difference in peak flow rate between regular smokers (mean (SD) 463 (100)) and never smokers $(454(88))$ aged 17 years.

\section{RESPONSE TO COUNSELLING}

Of the 43 regular smokers who received counselling, $60 \%$ (26) made an agreement with the practice doctor or nurse to give up, $14 \%$ (6) said they might, and $23 \%$ (10) declined; one result was unknown.

Advice as given in the study would take about 20 minutes of the doctor's or practice nurse's time for each patient. Reimbursement for similar adolescent health promotion clinics is being considered by the Royal College of General Practitioners under the North West Thames faculty. If only a $10 \%$ reduction in prevalence could be achieved by discouraging non-smokers from starting and smokers from continuing, this would mean a cost in the order of $£ 250$ per smoker avoided.

\section{Discussion}

Teenagers are considered low consulters in general practice and there was some doubt about their likely attendance. The $73 \%$ response rate, however, compares well with adult studies such as the general practice research framework adult lifestyle trial, which had a response rate of $61 \% .^{18}$ The other study to call in adolescents to general practice achieved a $50 \%$ attendance rate on a single invitation. ${ }^{19}$

Saliva cotinine concentration differentiated smokers from non-smokers and also non-smokers exposed to family passive smoking from those who were not, showing an upward gradient from father only to both parents smoking, confirming previous reports. ${ }^{20} \mathrm{~A}$ recent study reported that household exposure to 25 or more smoker years in childhood and adolescence doubles the risk of lung cancer. ${ }^{21}$ Measurable physiological effects of smoking are shown even at these young ages. Despite having a mean body mass index higher by $1 \cdot 5$, smokers registered a mean systolic blood pressure lower by about $6 \mathrm{~mm} \mathrm{Hg}$. This agrees with the report of Green et al that although cigarette smoking produces an acute rise in blood pressure in adults, smokers have lower blood pressure, which is not explained by differences in age, weight, alcohol intake, or physical activity. ${ }^{22}$ They postulate that as smokers tend to have higher heart rates and smoking seems to produce increased peripheral resistance, the reduction in blood pressure is most probably the result of reduced stroke volume. Similar effects are reported for 15 year olds in New Zealand. ${ }^{23}$ There was, however, no evidence from the peak flow rates in the present study of reduced lung function in general. This may reflect the short duration of smoking or that sophisticated measures of lung function were not made, but underlines benefits at this age of stopping smoking before lung function is obviously reduced.

Significantly higher body mass of smokers could be explained by reduced exercise and different dietary patterns. There is no reason to think that it is directly related to smoking, but it suggests that smoking does not necessarily keep adolescents slim. Smoking seems to be related to a constellation of behaviours including more frequent use of alcohol and reduced exercise and sleep.

There is evidence in the study that smokers, particularly girls, were considerably more likely to have health problems and that this was due to more allergic problems, notably asthma. Non-smokers had the expected national prevalence for their age whereas the prevalence in smokers was relatively high. Cigarette smoke has been shown to exacerbate and possibly trigger asthmatic reaction. ${ }^{24}$ One fifth of the asthmatic adolescents were regular smokers, and this must be an important issue for their management.

The increased risks of smoking for women taking oral contraceptives have been well documented, ${ }^{25}$ although it is not clear to what extent these risks hold for those taking very low oestrogen pills. A high proportion of ex-smokers were taking the pill, which may reflect a decision to give up smoking when starting the pill or a reluctance by general practitioners to prescribe the pill to current smokers. Even so, as many as $8 \%$ of 17 year old girls were both taking the pill and smoking regularly. Prescribing oral contraception may offer a good opportunity for discussing the risks of smoking.

Most smokers even at these young ages want to give up the habit, and $60 \%$ were willing to enter into a smoking cessation agreement with the doctor or nurse. This accords with findings of a study on adults that the doctor was considered an appropriate person to advise on health and lifestyle. ${ }^{26} \mathrm{~A}$ larger study is required to evaluate the effectiveness of advice given in general practice on adolescent health and lifestyle and the relative effectiveness of counselling by doctors and practice nurses.

An unexpected bonus of the study, expressed by practice staff, was the opportunity to lay the foundations of a good adult relationship, based on valuing positive health, with young patients, many of whom had previously been seen only rarely and during brief consultations for childhood ailments. The practice staff reported seeing rather few adolescent smokers. At these ages, particularly 13 and 15 years, regular smokers are very much in the minority and in fact the 
staff were seeing the number expected. It was also observed that non-smokers seemed firm in their intention not to smoke. Such intentions may be misleading. Only $6 \%$ of children think they will be regular smokers when they leave school, ${ }^{2}$ but if current rates reported in the general household survey continue as many as $37 \%$ will be regular smokers by their early $20 \mathrm{~s}$. At these rates one in three teenagers stating an intention not to smoke is likely to become a regular smoker within the next few years. There is clearly much to be done to strengthen and reinforce the early intention not to become a smoker, and this study suggests that most adolescents would welcome such an initiative from general practice.

Working party: David Simpson, John Davies, Jennifer Charlton, Julian Tudor Hart, Mary Tudor Hart, Andrew Haines, Godfrey Fowler, Paula Morgan, Martin Jarvis, Joy Townsend, Helen Wilkes.

We thank Dr David Davidson, Dr Michael Cripwell, Dr John Davies, Dr Julian Tudor Hart, Dr Susan Hunt, Jennifer Charlton, Mary Tudor Hart, and Paula Morgan for taking part in the study; Dr Paul Roderick and Dr James Connelly for helpful comments; and Dr Tom Meade for advice and support.

1 Office of Population Censuses and Surveys. Cigarette smoking 1972-1988. London: HMSO, 1990. (SS 90/1.)

2 Lader D, Matheson J. Smoking among secondary school children in 1990. London: HMSO, 1991.

3 Catford JC, Nutbeam D, Woolaway M. Effectiveness and cost benefits of smoking education. Community Medicine 1984;6:264-72.

4 Doll R. Age distribution of cancer: implications for models of carcinogenesis. fournal of the Royal Statistical Society (A) 1971;134:133-6.

5 Townsend JL. Smoking and lung cancer: a cohort data study of men and Townsend JL. Smoking and lung cancer: a cohort data study of men and
women in England and Wales 1935-1970. Fournal of the Royal Statistical women in England and Wales 1935

6 Balding J. Young people in 1988. Exeter: HEA Schools Health Education Unit, Exeter University, 1989

7 Macfarlane A, McPherson A, McPherson K, Ahmed L. Teenagers and their health. Arch Dis Child 1987;62:1125-9.
8 Murray M, Swann AO, Clarke G. Long term effect of a school based antismoking programme. J Epidemiol Community Health 1984;38:247-52.

9 Cleary PD, Hitchcock JL, Semmers N, Flinchbaugh L, Pinney J. Adolescen smoking: research and health policy. Cambridge, Massachusetts: Institute for the Study of Smoking Behaviour and Policy, 1986.

10 Jamrozik K, Vessey M, Fowler G, Wald N, Parker G, Van Vanakis H. Controlled trial of three different antismoking interventions in general practice. BMf 1984;288:1499-503.

11 Richmond R, Webster I. Evaluation of general practitioners' use of a smoking intervention programme. Int $\mathcal{f}$ Epidemiol 1985;14:396-401.

12 Russell MAH, Wilson C, Taylor C, Baker CD. Effective general practitioners' advice against smoking. $B M 7$ 1979;ii:231-5.

3 Townsend JL. Economic and health consequences of reduced smoking. In Williams A, ed. Health and economics. London: Macmillan, 1987:139-61.

4 Williams A. Economics of coronary artery bypass grafting. BMF 1985;291: 326-9.

15 Health Education Authority. A smoker's guide to giving up. London: HEA 1987.

16 Cancer Research Campaign/Tacade. Packing it in. London: CRC/Tacade, 1988

17 McNeill AD, Jarvis MJ, West R, Russell MAH, Bryant A. Saliva cotinine as an indicator of cigarette smoking in adolescents. $\mathrm{Br} \mathcal{J}$ Addict 1987;82: $1355-60$.

18 Cutler SF, Wallace PG, Haines AP. Assessing alcohol consumption in general practice patients - a comparison between questionnaire and interview (findings of the Medical Research Council's General Practice Research Framework study on lifestyle and health). Alcohol Alcohol 1988;23:441-50.

19 Donovan CF, McCarthy S. Is there a place for adolescent screening in general practice? Health Trends 1988;2:20;64.

20 Jarvis MJ, Russel MAH, Feyerabend C, Eiser J, Morgan M, Gammage P, Gray E. Passive exposure to tobacco smoke: saliva cotinine concentrations in a representative population sample of non-smoking schoolchildren. $B M$ 1985;291:927-9.

21 Janerich DT, Thompson WD, Varela LR, Greenwald P, Chorost P, Tucci C. Lung cancer and exposure to tobacco smoke in the household. $N$ Engl 7 Med 1990;323:632-6.

22 Green M, Jucha E, Luz Y. Blood pressure in smokers and non smokers: epidemiological findings. Am Heart $f$ 1986;111:932-40.

23 St George IM, Williams S, Stanton W, Silva PA. Smoking and blood pressure in 15 year olds in Dunedin in New Zealand. BMJ 1991;302:89-90.

24 Kershaw CR. Passive smoking, potential atopy and asthma in the first five years. $7 R$ Soc Med 1987,80:683-8.

25 Croft $P$, Hannaford PC. Risk factors for acute myocardial infarction in women: evidence from the Royal College of General Practitioners' oral contraceptive evidence from the Royal College

26 Wallace PG, Haines AP, Brennan PJ. Are GPs doing enough to promote healthy lifestyle? Findings of the MRC General Practice Research Framework study on lifestyle and health. $B M \mathcal{F} 1987 ; 294: 940-2$.

(Accepted 23 fuly 1991 )

\title{
Elderly and younger patients selected to undergo coronary angiography
}

\author{
A T Elder, T R D Shaw, C M Turnbull, I R Starkey
}

\section{Abstract}

Objective-To establish and compare the characteristics of older ( $\geqslant 70$ years) and younger patients with chest pain selected to undergo coronary angiography and by analysis of their subsequent management to assess the value of coronary angiography for older patients with chest pain.

Design-Retrospective analysis of clinical case notes and coronary angiography reports.

Setting-Cardiology department with referral population of one million in an Edinburgh hospital.

Patients - 134 consecutive patients with chest pain aged 70 years or over investigated by coronary angiography between 1978 and 1988; 134 randomly selected patients aged under 70 investigated over the same period.

Main outcome measures-Clinical and angiographic features at time of angiography and management after angiography.

Results-Older patients represented a small, but increasing, proportion of those investigated. Older patients had more severe symptoms at the time of angiography, were taking more antianginal drugs, and had had their symptoms for longer than younger patients. At angiography more older patients had triple vessel coronary disease, left main stem stenosis, or left ventricular impairment. After angiography similar proportions of older and younger patients underwent coronary artery surgery, with more elderly patients requiring urgent operation; although operative mortality was higher for elderly patients, symptomatic benefit was similar to that in younger patients.

Conclusions-Older patients with angina selected to undergo coronary angiography and subsequent coronary surgery have more severe symptoms and underlying cardiac disease. Earlier referral and investigation might yield a population with lower operative risk. Selection of patients for coronary angiography and coronary artery surgery should be based on the potential for benefit and should avoid "agism."

\section{Introduction}

The number of elderly people in the United Kingdom has risen progressively and there has been an associated increase in the prevalence of age related conditions such as angina pectoris. Although cardiology departments have consequently experienced an increase in the number of elderly patients referred for investigation of coronary artery disease, such patients still represent only a small proportion of the total number undergoing coronary angiography. To assess the value of coronary angiography in elderly patients with angina we reviewed the angiographic findings and clinical features and outcome of patients aged 70 years or more who had coronary angiography during 1978-88
Correspondence to:

Dr Elder.

BMf 1991;303:950-3 